\title{
Venous thromboembolism in patients immobilised at home
}

To the Editor:

The natural history of venous thromboembolism (VTE), its impact on outcome and the rationale for prophylaxis are well established for hospitalised, acutely ill medical patients [1-10], but are less clear for nonhospitalised immobilised patients. Current guidelines for antithrombotic therapy recommend the use of prophylaxis in hospitalised, acutely ill medical patients, and suggest against its use in chronically immobilised persons at home and in patients with isolated lower-leg injuries requiring leg immobilisation [11]. However, there are no suggestions on the use of VTE prophylaxis in acutely ill medical patients immobilised at home.

We used the Registro Informatizado de Enfermedad TromboEmbólica (RIETE) registry database to compare the clinical characteristics, use of prophylaxis and 3-month outcome of all VTE patients with recent immobilisation (bed rest with bathroom privileges in the 2-months prior to VTE) for $\geqslant 4$ days according to being immobilised at home or in hospital [12-14]. We used multiple logistic regression analyses to identify factors predicting the prescription of VTE prophylaxis and factors predicting the risk of fatal pulmonary embolism (PE) within the first 3 months. The following covariates were selected: sex, age, weight, chronic lung disease, heart failure, creatinine clearance levels, recent bleeding, prior VTE, oestrogen use, cancer, initial VTE presentation, reason, site and duration of immobilisation, and use of anti-platelet or nonsteroidal anti-inflammatory drugs at baseline. SPSS (version 15: SPSS Inc., Chicago, IL, USA) was used for statistical management of data.

Up to January 2014, 50764 patients with acute VTE were enrolled in RIETE. Of these, 9120 (18\%) had recent immobility: $5960(12 \%)$ at home, $2429(4.8 \%)$ in hospital and $731(1.4 \%)$ at a nursing home (nursing home patients were not considered in the study). Among patients immobilised at home, $38 \%$ had an acute medical illness, $28 \%$ had recent trauma, 25\% chronic immobility and $9.5 \%$ had other reasons (table 1). Among those immobilised in hospital, 70\% had an acute medical illness, $7.7 \%$ trauma, $6.5 \%$ chronic immobility and $9.5 \%$ other. The most common traumatic injuries at home were lower-limb fractures (22\%), contusions (19\%), sprained ankle (13\%) and tendon injuries (10\%). The most common in hospital were multiple fractures (43\%) and cranioencephalic trauma (19\%).

Patients immobilised at home were less likely to present with PE (50\% versus 53\%; OR 0.87, 95\% CI $0.79-$ 0.95 ) and less likely to have chronic lung disease, heart failure, cancer, anaemia or recent bleeding than those immobilised in hospital. Duration of immobility was $>4$ weeks in $38 \%$ of patients at home and in 7.4\% in hospital (OR 7.64, 95\% CI 6.50-8.98) and the proportion of patients who had received VTE prophylaxis was $12 \%$ versus $56 \%$, respectively (OR $0.11,95 \%$ CI $0.10-0.12$ ). Among patients immobilised at home, $6.2 \%$ of those with an acute medical illness, $27 \%$ with trauma, $4.0 \%$ with chronic immobilisation and $10 \%$ immobilised for other reasons received VTE prophylaxis. Among those in hospital, the proportions were $62 \%, 58 \%, 36 \%$ and $37 \%$, respectively.

Most patients (90\%) in both subgroups received initial therapy with low-molecular-weight heparin, with no differences in mean daily doses. Then, $65 \%$ of patients immobilised at home and $52 \%$ of those in hospital received long-term therapy with vitamin $\mathrm{K}$ antagonists. During the first 3 months of therapy, the rate of VTE recurrences (OR 0.66, 95\% CI 0.48-0.92), major bleeding (OR 0.69, 95\% CI 0.53-0.89), all-cause death (OR 0.70, 95\% CI $0.61-0.80$ ) and fatal bleeding (OR 0.53, 95\% CI 0.32-0.87) were significantly lower in patients immobilised at home but the mortality due to PE was similar (OR 1.05, 95\% CI 0.74-1.49). The 90-day rate of fatal PE among patients immobilised at home was $2.7 \%$ in the acutely ill, $0.4 \%$ in those with trauma and $2.4 \%$ in those with chronic immobilisation. Among patients immobilised in hospital, rates were $2.1 \%, 0.5 \%$ and $1.3 \%$, respectively.

On multivariable analysis, prior VTE (OR 1.69, 95\% CI 1.30-2.18) and recent trauma (OR 5.55, 95\% CI 4.35-6.67) were associated with increased rates of VTE prophylaxis at home, while length of immobility $<7$ days (OR 0.30, 95\% CI 0.24-0.43) and use of nonsteroidal anti-inflammatory drugs (OR 0.62, 95\% CI 0.45-0.85) were associated with a lower risk. Moreover, initial VTE presentation as PE (OR 15.0, 95\% CI 6.58-34.3), immobility for an acute medical illness (OR 4.21, 95\% CI 1.80-9.84), cancer (OR 2.96, 95\% 
CI 1.98-4.42) and renal insufficiency (OR 2.63, 95\% CI 1.67-4.13) were independently associated with an increased risk of dying of PE among patients immobilised at home.

Our data reveal that the amount of patients arriving at the hospital with acute VTE developing after immobilisation at home was over two-fold higher than the amount of patients developing PE while staying in hospital. Patients at home had different reasons for immobilisation, fewer comorbidities and a longer length of immobilisation than those in hospital, but their 90-day PE-related mortality was the same. Hence, the amount of patients dying of PE after being immobilised at home was over two-fold higher than in those immobilised in hospital. Interestingly, however, the use of VTE prophylaxis in patients at home was much lower than in hospital (12\% versus $56 \%$, respectively).

In our series, $6.2 \%$ of acutely ill medical patients and $27 \%$ of trauma patients did receive prophylaxis, and their rates of fatal PE were $2.7 \%$ and $0.4 \%$, respectively. Thus, physicians were less likely to prescribe prophylaxis to patients at the highest risk of dying of $\mathrm{PE}$ and most likely to prescribe it to those at lowest risk. This is probably because there are no randomised clinical trials demonstrating the effectiveness and safety of VTE prophylaxis in acutely ill medical patients at home. To our knowledge, no such trials are in progress, probably due to logistical problems of performing studies at home. Hence, we cannot reasonably expect any reduction in the burden of VTE in this population in the near future.

In our series, immobilisation for an acute medical illness was associated with an increased risk of dying of PE, irrespectively of the length of immobility. This is important because patients in bed for $<7$ days at home received the lowest rates of prophylaxis. Thus, we suggest that some patients with acute medical illnesses (particularly if they also have renal insufficiency or cancer) might benefit from VTE prophylaxis, even if bedridden at home.

The present study has several limitations. Patients were not treated with a standardised anticoagulant regimen and sudden unexplained deaths were not considered as fatal PE in this analysis (only confirmed PEs were considered). Thus, the rate of fatal PE may be underestimated, especially after hospital discharge. Strengths of the current analysis include that a large number of consecutive unselected patients were enrolled and that fatal PE is by far the most important outcome during the treatment of acute PE.

In summary, the amount of patients arriving to the hospital with acute VTE after immobilisation at home was over two-fold higher than the amount of patients with VTE appearing during hospital stay. Those with an acute medical illness and those with renal insufficiency or cancer were at increased risk of dying of $\mathrm{PE}$, but only few had received prophylaxis. Randomised trials should be conducted to assess the

TABLE 1 Use of thromboprophylaxis and 90-day rates of fatal pulmonary embolism (PE), according to the reason, duration and site of immobilisation

\begin{tabular}{|c|c|c|c|c|c|c|}
\hline & \multicolumn{3}{|c|}{ At home } & \multicolumn{3}{|c|}{ In hospital } \\
\hline & Patients & Prophylaxis & Fatal PE & Patients & Prophylaxis & Fatal PE \\
\hline All patients & 5960 & $717(12)$ & $111(1.9)$ & 2429 & $1351(56)$ & 43 (1.8) \\
\hline Acute medical illness & 2241 & $140(6.2)$ & $60(2.7)$ & 1690 & $1041(62)$ & $35(2.1)$ \\
\hline Infection & 609 & $31(5.1)$ & $8(1.3)$ & 797 & $507(64)$ & $16(2.0)$ \\
\hline Arthropathy & 819 & 32 (3.9) & $6(0.7)$ & 36 & $13(36)$ & $1(2.8)$ \\
\hline Cancer & 369 & $38(10)$ & $31(8.4)$ & 199 & 114 (57) & $7(3.5)$ \\
\hline Respiratory insufficiency & 200 & $11(5.5)$ & $1(0.5)$ & 163 & $114(70)$ & $3(1.8)$ \\
\hline Acute stroke & 84 & $13(15)$ & $4(4.8)$ & 182 & $91(50)$ & $3(1.6)$ \\
\hline Heart insufficiency & 111 & $12(11)$ & $9(8.1)$ & 131 & $97(74)$ & $3(2.3)$ \\
\hline Ischaemic heart disease & 13 & $3(23)$ & 0 & 89 & $63(71)$ & 0 \\
\hline Inflammatory bowel disease & 22 & 0 & $1(4.6)$ & 47 & $16(34)$ & 0 \\
\hline Other & 14 & 0 & 0 & 46 & $26(57)$ & $2(4.3)$ \\
\hline Trauma & 1677 & 459 (27) & $6(0.4)$ & 187 & $108(58)$ & $1(0.5)$ \\
\hline Chronic immobilisation & 1477 & $59(4.0)$ & $35(2.4)$ & 159 & $57(36)$ & $2(1.3)$ \\
\hline Dementia & 951 & $39(4.1)$ & $25(2.6)$ & 108 & $27(25)$ & $1(0.9)$ \\
\hline Lower limb paralysis & 526 & $20(3.8)$ & $10(1.9)$ & 51 & $30(59)$ & $1(2.0)$ \\
\hline $\begin{array}{l}\text { Other reasons } \\
\text { Duration of immobilisation }\end{array}$ & 565 & $59(10)$ & $10(1.8)$ & 393 & 145 (37) & $5(1.3)$ \\
\hline$<7$ days & 1226 & $78(6.4)$ & $22(1.8)$ & 944 & $483(51)$ & $22(2.3)$ \\
\hline $1-4$ weeks & 2398 & $363(15)$ & $36(1.5)$ & 1272 & 740 (58) & $18(1.4)$ \\
\hline $5-8$ weeks & 567 & $128(23)$ & $10(1.8)$ & 112 & $74(66)$ & $1(0.9)$ \\
\hline$>8$ weeks & 1670 & 135 (8.1) & $41(2.5)$ & 67 & $36(54)$ & $2(3.0)$ \\
\hline
\end{tabular}


effectiveness and safety of VTE prophylaxis in patients immobilised at home for an acute medical illness. In the meantime, some of these patients (particularly if they also have renal insufficiency or cancer) might benefit from VTE prophylaxis.

0 $@$ ERSpublications

Fatal PE after immobility at home was more frequent than after immobility in hospital http://ow.ly/J0UIr

Raquel López-Reyes ${ }^{1}$, Dolores Nauffal ${ }^{1}$, Marta Ballester ${ }^{1}$, José Manuel Martín-Antorán ${ }^{2}$, Marta Saraiva de Sousa ${ }^{3}$, Antoni Riera-Mestre ${ }^{4}$, Justo Ruiz-Ruiz ${ }^{5}$, Carmen Fernández-Capitán ${ }^{6}$, Fernando Uresandi ${ }^{7}$ and Manuel Monreal ${ }^{8,9}$ on behalf of the RIETE investigators ${ }^{10}$

${ }^{1}$ Dept of Pneumonology, Hospital Universitario La Fe, Valencia, Spain. ${ }^{2}$ Dept of Haemostasis and Thrombosis, Hospital Río Carrión, Valencia, Spain. ${ }^{3}$ Dept of Internal Medicine, Centro Hospitalar Gaia/Espinho, EPE, Vila Nova de Gaia, Portugal. ${ }^{4}$ Dept of Internal Medicine, Hospital Universitari de Bellvitge, Barcelona, Spain. ${ }^{5}$ Dept of Internal Medicine, Hospital de Fuenlabrada, Madrid, Spain. ${ }^{6}$ Dept of Internal Medicine, Hospital Universitario La Paz, Madrid, Spain. ${ }^{7}$ Dept of Pneumonology, Hospital de Cruces, Barakaldo, Spain. ${ }^{8}$ Dept of Internal Medicine, Hospital Universitari Germans Trias i Pujol, Badalona, Spain. ${ }^{9}$ Universidad Católica de Murcia, Murcia, Spain. ${ }^{10}$ For a list of the RIETE investigators see the Acknowledgements section.

Correspondence: Manuel Monreal, Servicio de Medicina Interna, Hospital Germans Trias i Pujol, Carretera del Canyet s/n., 08916 Badalona (Barcelona), Spain. E-mail: mmonreal.germanstrias@gencat.cat

Received: Nov 282014 | Accepted after revision: Jan 292015 | First published online: March 052015

Support statement: We express our gratitude to Sanofi Spain for supporting this Registry with an unrestricted educational grant. We also express our gratitude to Bayer Pharma AG for supporting this Registry. Bayer Pharma AG's support was limited to the part of RIETE outside Spain, which accounts for a $21.94 \%$ of the total patients included in the RIETE Registry. Funding information for this article has been deposited with FundRef.

Conflict of interest: Disclosures can be found alongside the online version of this article at erj.ersjournals.com

Acknowledgements: The coordinator of the RIETE Registry was Manuel Monreal (Spain). The RIETE Steering Committee members were Hervè Decousus (France), Paolo Prandoni (Italy) and Benjamin Brenner (Israel). The RIETE National Coordinators were Raquel Barba (Spain), Pierpaolo Di Micco (Italy), Laurent Bertoletti (France), Sebastian Schellong (Germany), Inna Tzoran (Israel), Abilio Reis (Portugal), Marijan Bosevski (Republic of Macedonia), Henri Bounameaux (Switzerland), Radovan Malý (Czech Republic) and Philip Wells (Canada). The RIETE Registry Coordinating Center was S\&H Medical Science Service, Madrid, Spain.

The members of the RIETE group were as follows. Spain: M. Alcalde-Manero, V. Andújar, J.I. Arcelus, R. Barba, M. Barrón, B. Barrón-Andrés, J. Bascuñana, A. Blanco-Molina, I. Casado, F. Conget, C. de Ancos, F. del Molino, J. del Toro, J.A. Díaz, C. Falgá, A.I. Farfán, C. Fernández-Capitán, C. Font, L. Font, P. Gallego, F. García-Bragado, V. Gómez, J. González, D. González-Marcano, E. Grau, R. Guijarro, J. Gutiérrez, L. Hernández, S. Hernández-Huerta, L. Jara-Palomares, M.J. Jaras, D. Jiménez, J.L. Lobo, L. López-Jiménez, L. López-Montes, R. López-Reyes, J.B. López-Sáez, M.A. Lorente, A. Lorenzo, M. Macià, O. Madridano, P.J. Marchena, J.M. Martín-Antorán, F. Martín-Martos, M. Mellado, M. Monreal, M.V. Morales, D. Nauffal, J.A. Nieto, M.J. Núñez, R. Otero, B. Pagán, J.M. Pedrajas, G. Pérez-Rus, M.L. Peris, I. Pons, J.A. Porras, A. Riera-Mestre, A. Rivas, M.A. Rodríguez-Dávila, P. Román, V. Rosa, N. Ruiz-Giménez, J. Ruiz, A. Sampériz, R. Sánchez, O. Sanz, S. Soler, J.M. Suriñach, G. Tiberio, R. Tirado, J. Trujillo-Santos, F. Uresandi, B. Valero, R. Valle, J. Vela, C. Vilar, A. Villalobos and J. Villalta. Argentina: P. Malfante P. Belgium: P. Verhamme and T. Vanassche. Brazil: T. Gadelha. Canada: P. Wells. Czech Republic: R. Malý and J. Hirmerova. France: L. Bertoletti, A. Bura-Riviere, F. Moustafa, D. Farge-Bancel, A. Hij, I. Mahe, A. Merah and I. Quere. Germany: S. Schellong. Israel: A. Braester, B. Brenner, I. Tzoran and D. Zeltser. Italy: A. Apollonio, G. Barillari, M. Ciammaichella, F. Dalla Valle, P. Di Micco, P. Ferrazzi, A. Guida, R. Maida, F. Pace, S. Pasca, C. Piovella, P. Prandoni, R. Re, L. Rota, E. Tiraferri, D. Tonello, A. Tufano, A. Visonà and B. Zalunardo. Portugal: A. Mondragão, J.L. Ribeiro de Almeida and M.S. Sousa. Republic of Macedonia: M. Bosevski and M. Zdraveska. Switzerland: A. Alatri, H. Bounameaux, L. Calanca and L. Mazzolai. Venezuela: J.C. Serrano.

We thank S\&H Medical Science Service for their quality control data, logistic and administrative support.

\section{References}

1 Heit JA, Silverstein MD, Mohr DN, et al. Risk factors for deep vein thrombosis and pulmonary embolism. A population-based case-control study. Arch Intern Med 2000; 160: 809-815.

2 Prandoni $\mathrm{P}$, Villalta $\mathrm{S}$, Tormene $\mathrm{D}$, et al. Immobilization resulting from chronic medical diseases: a new risk factor for recurrent venous thromboembolism in anticoagulated patients. J Thromb Haemost 2007; 5: 1786-1787.

3 Tapson VF, Hyers TM, Waldo AL, et al. Antithrombotic therapy practices in US hospitals in an era of practice guidelines. Arch Intern Med 2005; 165: 1458-1464.

4 Bergmann JF, Cohen AT, Tapson VF, et al. Venous thromboembolism risk and prophylaxis in hospitalised medically ill patients. The ENDORSE Global Survey. Thromb Haemost 2010; 103: 736-748.

5 Khoury $\mathrm{H}$, Welner S, Kubin $\mathrm{M}$, et al. Disease burden and unmet needs for prevention of venous thromboembolism in medically ill patients in Europe show underutilisation of preventive therapies. Thromb Haemost 2011; 106: 600-608.

6 Samama MM, Cohen AT, Darmon JY, et al. A comparison of enoxaparin with placebo for the prevention of venous thromboembolism in acutely ill medical patients. Prophylaxis in medical patients with Enoxaparin Study Group. N Engl J Med 1999; 341: 793-800.

7 Leizorovicz A, Cohen AT, Turpie AG, et al. Randomized, placebo-controlled trial of dalteparin for the prevention of venous thromboembolism in acutely ill medical patients. Circulation 2004; 110: 874-879. 
8 Dentali F, Douketis JD, Gianni M, et al. Meta-analysis: anticoagulant prophylaxis to prevent symptomatic venous thromboembolism in hospitalized medical patients. Ann Intern Med 2007; 146: 278-288.

9 Lloyd NS, Douketis JD, Moinuddin I, et al. Anticoagulant prophylaxis to prevent asymptomatic deep vein thrombosis in hospitalized medical patients: a systematic review and meta-analysis. J Thromb Haemost 2008; 6: 405-414.

10 Imberti D, Benedetti R, Ageno W. Prevention of venous thromboembolism in acutely ill medical patients after the results of recent trial with the new oral anticoagulants. Intern Emerg Med 2013; 8: 667-672.

11 Kahn SR, Lim W, Dunn AS, et al. Prevention of VTE in nonsurgical patients. Antithrombotic Therapy and Prevention of Thrombosis, 9th ed: American College of Chest Physicians Evidence-Based Clinical Practice Guidelines. Chest 2012; 141: Suppl., e195S-e226S.

12 Nauffal D, Ballester M, Lopez Reyes R, et al. Influence of recent immobilization and recent surgery on mortality in patients with pulmonary embolism. J Thromb Haemost 2012; 10: 1752-1760.

13 Monreal M, Kakkar AK, Caprini JA, et al. The outcome after treatment of venous thromboembolism is different in surgical and acutely ill medical patients: findings from the RIETE registry. J Thromb Haemost 2004; 2: 1892-1898.

14 Laporte S, Mismetti P, Décousus H, et al. Clinical predictors for fatal pulmonary embolism in 15,520 patients with venous thromboembolism: findings from the Registro Informatizado de la Enfermedad TromboEmbólica Venosa (RIETE) Registry. Circulation 2008; 117: 1711-1716.

\section{Noninterventional statistical comparison of BTS and CHEST guidelines for size and severity in primary pneumothorax}

To the Editor:

Primary spontaneous pneumothorax (PSP) occurs in apparently healthy young people with an incidence of 12.5 cases per 100000 per year [1]. Attempts to develop standardised care guidelines for this condition have been severely hampered by a lack of high-quality clinical research into this condition. The American College of Chest Physicians (CHEST) concluded in 2001 that "insufficient data exist...to develop an evidence-based document" and so produced a consensus statement based on expert opinion [2]. Similarly, the British Thoracic Society (BTS) 2010 guidelines are based predominantly on nonanalytical studies and expert opinion [3]. In both documents, the size of the presenting PSP is used to determine initial treatment. A "small" PSP without respiratory compromise is thought not to require intervention, while a "large" PSP has typically been treated either by aspiration or intrapleural drainage. Implicit in these definitions is the belief that large pneumothoraces will not respond well to conservative management. Remarkably, no consensus regarding the definition of PSP severity exists, with CHEST and the BTS each using different arbitrary measurements of the presentation chest radiograph. When these measurements were compared directly to one another, they showed poor correlation [4]. This lack of a clinically useful radiological biomarker for pneumothoraces requiring intervention hinders the development of evidence-based care of this condition. We wished to determine whether the BTS definition of large pneumothorax ( $>2 \mathrm{~cm}$ at the hilum) or CHEST definition $(>3 \mathrm{~cm}$ from apex to cupola) better predicts the requirement for intercostal chest drain (ICD) insertion.

A pilot study of 42 cases estimated the area under the receiver operator curve (ROC) to be between 0.92 and 0.95 for hilar and apical measurements. From this, we calculated that for an $80 \%$ power to detect a 0.03 difference with 5\% two-sided significance, 115 cases were required. Patients from 13 UK National Health Service hospitals were recruited prospectively from February 2012 to May 2013. The study was approved by the research and development departments of all participating hospitals. Inclusion criteria were diagnosis of PSP, and age between 16 and 60 years. Cases of tension pneumothorax and those $>50$ years with a smoking history of $>5$ pack-years were excluded. Case notes and presentation radiographs were reviewed by the research team, who were all senior or middle-grade, UK-trained respiratory and emergency physicians trained to follow BTS guidelines. Verification of adherence to BTS guidelines was performed by the lead authors, and was based on reviewing case notes and chest radiographs. Measurements of the interpleural distances were recorded at the level of the ipsilateral hilum, and between the apex of the lung and the cupola. Current BTS guidelines state that in noncompromised patients with a 